\title{
Changes in University Students' Perceptions towards a Two-Week Summer English Immersion Program
}

\author{
Meihua Liu (Corresponding author) \\ Department of Foreign Languages \& Literatures, Tsinghua University, Beijing, 100084, China \\ E-mail: ellenlmh@yahoo.com \\ Yang $\mathrm{Hu}$ \\ Department of Foreign Languages \& Literatures, Tsinghua University, Beijing, 100084, China \\ E-mail: yang-hu@mail.tsinghua.edu.cn \\ Yan Peng \\ Department of Foreign Languages \& Literatures, Tsinghua University, Beijing, 100084, China \\ E-mail: pennypeng@163.com
}

Received: 18-09-2016

Accepted: 10-12-2016

Advance Access Published: January 2017

Published: 01-03-2017

doi:10.7575/aiac.ijalel.v.6n.2p.127

URL: http://dx.doi.org/10.7575/aiac.ijalel.v.6n.2p.127

\begin{abstract}
The present research examined how university students perceived a 2-week summer English immersion program organized and designated by Chinese teachers of English in a highly prestigious university in Beijing and whether their perceptions changed during the period. Data included 208 surveys and 19 informal interviews in week 1 and 207 surveys and 19 interviews in week 2 (the participants were largely the same in both weeks). Analyses of the data showed that in both weeks, most students considered the courses interesting and liked most of them for similar reasons (e.g., being interesting and having much participation), that the program improved students' English abilities in listening, speaking, reading and writing as well as overall English proficiency, and that the program enhanced students' interpersonal communication ability, confidence in using English, knowledge of the culture of English-speaking countries, interest in and motivation to learn English. The results also revealed that the participants tended to become more positive about the program, have a more comprehensive view of the program and assess it more objectively toward the end of the program. Evidently, the program helped the students in various aspects. To better help students, it is useful to do needs analyses prior to the program so that more acceptable courses and activities can be designed and offered.
\end{abstract}

Keywords: perception, change, immersion program

\section{Introduction}

As English increasingly becomes the lingua franca for international communication in diverse fields of work, greater importance has been attached to English and high levels of English proficiency has become crucial in the world. To help students better learn English, various immersion programs have been delivered in addition to conventional English language instruction. In most immersion programs, students receive huge amounts of instruction in the target language (TL), thus the effects of which have been investigated from different aspects (Baker, 2011; Garcia \& Torres-Ayala, 1991; Gebauer, Zaunbauer \& Moller, 2013; Genesee, 2004; Rugasken \& Harris, 2006; Swain \& Lapkin, 1989). Nevertheless, little research can be found on the changes of students' perceptions towards immersion programs, which is exactly the focus of the present research.

To increase students' contact and access to English, a Summer English Immersion Program was organized and designated by Chinese teachers of English in 2014 in a highly prestigious university in Beijing and continued till now, which was a 2 -week program including both classroom and field study situations. The primary goal was to improve students' English listening and speaking skills while having fun. The present research examined how the students perceived the 2-week summer English immersion program and whether their perceptions changed during the period.

\section{Literature Review}

As widely agreed, language is the primary medium through which speakers participate in social interactions, and different types and degrees of participation in a target language (TL) community determine how proficient the speaker is in the TL (Jimenez, 2003; Shively, 2008; Vygotsky, 1978). This is why contact and use of the TL is so critical in second/foreign language (SL/FL) acquisition (Kang, 2005; MacIntyre, Clément, Dörnyei \& Noels, 1998; Martinsen, 2011). To increase students' contact and access to the TL, various immersion programs have been established, the effects of which have been discussed in diverse SL/FL situations (Alcòn-Soler, 2015; DeKeyser, 2007; Liskin- 
Gasparro, 1998; Pang \& Liu, 2005; Rugasken \& Harris, 2006; Savage \& Hughes, 2014; Swain \& Lapkin, 1989; Walker \& Tedick, 2000).

Language immersion programs are to "provide input from native language models in naturalistic non-monitored situations (Garcia \& Torres-Ayala, 1991, p.439). Conducted in various forms, language immersion programs generally aim to immerse students in the TL as if they were born into it and learn it as they did their mother tongue. Thus, the programs often offer a blend of classroom teaching and field experiences, as determined by the mission and objectives specified by the program administrators. If implemented properly, language immersion programs are very efficient in improving SL/FL acquisition and academic achievements (Cummins, 1983) and are thus highly popular. Rifkin (2005) found that the immersion-based instruction was more efficient than the traditional classroom with students developing listening, reading, speaking and writing skills of the TL as well as grammar/syntax knowledge. In order to explore students' perceptions of a school-based immersion program, Pang and Liu (2005) recruited 1331 Macao secondary school students who answered a 15-item self-designed survey. The study revealed that (a) most students were not motivated to learn spoken English, (b) the students at higher grade levels tended to be significantly more motivated and held more positive attitudes towards the program, (c) male students were significantly more motivated and thought more highly of the program than their female counterparts, and (d) the students' English-learning motivation and attitudes towards the program were significantly positively correlated with their English proficiency. The researchers thus suggested that an integration of different varieties of English-speaking activities might be more interesting and motivating to the students, and that a friendly and low-anxious classroom-learning environment might be better for the students to communicate with each other freely in the TL, as discussed in Young (1991).

Rugasken and Harris (2006) assessed how well the 15-day English camp assisted Thai college students in language acquisition through writing. One camp leader and 3 students participated in the study, focusing on how the leader developed her program about writing for the students during the camp. The study revealed that the students improved greatly in terms of word usage (e.g., total words, and different types of words such as nouns, verbs, adjectives, adverbs, conjunctions, articles, prepositions and pronouns) and the total number of sentences produced in the pre- and postwritings. Thus the researchers claimed that the immersion program improved not only students' language acquisition but also their cultural understanding. To explore cross-language transfer between German (first language) and English (second language) reading fluency and reading comprehension, Gebauer, Zaunbauer and Moller (2013) recruited 220 German elementary school students who were enrolled in English partial immersion programs. The study revealed moderate cross-language transfer when controlling for autoregressive effects. The researchers explained that the immersion program provided plentiful opportunities for academic reading in English at school and claimed that skills necessary for successful reading could be acquired in an immersion context and transferred to the first language.

As reviewed above, though immersion programs are highly popular in various SL/FL contexts and are discussed by many researchers, more research is called for since immersion programs in SL/FL contexts are not adequately studied. For this reason, the present research aimed to examine how university students perceived a 2-week summer English immersion program organized and designated by Chinese teachers of English in a highly prestigious university in Beijing and how their perceptions changed during the period. To achieve this aim, the following questions were formulated:

(1) How do the students perceive the summer English immersion program?

(2) Is there any change in the students' perceptions of the program during the period?

\section{The Study}

\subsection{The context}

To improve English proficiency of non-English majors, the university where the present study was conducted offered a two-week summer English immersion program for first-year students at the beginning of their first summer break in the university. The basic features of the program were that English was the medium of instruction, that the teachers were bilingual, and that the students were at similar English proficiency levels. The courses designed for this program aimed to improve the students' English listening, speaking, reading and writing skills as well as cultural awareness. The courses offered included Public Speaking, Classic Reading, Film Dubbing, and Debating in the morning, and MOOC (Oral Communication for EFL Learners) in the afternoon. The daily program was scheduled as: 3 hours of classroom instruction (lecturing + discussion + practice) in the morning, and self-monitored MOOC learning in the afternoon. Each student had to attend all the five courses, with one course every morning (with Film Dubbing twice a week). To enhance students' chances of participation, all the courses in the morning were task-based. In the first week, teachers explained the course requirements first and then assigned the task(s), the students then started to prepare and practice. The teachers were there to provide help. In the second week, the students performed the tasks in class individually or collaboratively, which was scored by the teachers for each course. For the 2016 summer program, about 900 students registered for the program when the present study was conducted.

\subsection{Participants}

In week 1, 208 (156 male, 32 female, 20 unknown) students registering in the program answered the questionnaires, 19 of whom were interviewed. The students generally majored in diverse subjects such as electronic engineering, computer engineering, material engineering, mathematics, pharmacy, Japanese and news. 207 students of the same population answered the same questionnaires again in week 2, of whom the same 19 students were interviewed. 


\subsection{Instruments}

The data were gathered via questionnaires and informal semi-structured interviews, as detailed below. Perceptions of the Summer English Program Questionnaire. This 27-item Perceptions of the Summer English Program Questionnaire (PSEPQ) was developed with reference to Garnder's (1985) Attitudes/Motivation Battery Questionnaire. PSEPQ consisted of 26 closed statements and 1 open-ended question "I do or don't like the program because __. The closed statements covered such issues as attitudes towards the courses (items 1-8), and roles of the program in increasing their exposure to English (items 9-12) and improving their learning of English (items 14-22), and overall comments on the program (items 23-26).

Background Information Questionnaire. This 3-item Background Information Questionnaire aimed to gather such information about the participants as name, gender and discipline.

Semi-structured interview. To elicit more insider views of the program and complement the survey data, 19 of the survey respondents were randomly chosen for informal semi-structured interviews. The interview guide had 15 leading questions, covering such issues as attitudes towards the courses and roles of the program in increasing their exposure to English and improving their learning of English, and overall comments on and suggestions for bettering the program.

Procedure. Since the program lasted for 2 weeks, to better explore the students' perceptions of the program, data were collected at the end of each week from basically the same students with the same instruments. At the end of the morning course of each week, the students answered the questionnaires in class, 19 of whom were then informally interviewed.

\subsection{Data analysis}

The survey data were analyzed using SPSS 20. Means and standard deviations were computed to determine students' perceptions of the summer English program at the end of each week, then paired samples t-tests were run on each survey item to explore whether the difference in perceptions between the two weeks was statistically significant. All the interview data were transcribed, double-checked, and then subjected to open coding, together with the responses to the open-ended question, to identify their perceptions of the program (Richards, 2009). When coding the qualitative data, each interviewee was assigned a pseudonym, and a number was used for each open-ended question respondent. The number and pseudonym remained the same in both weeks.

\section{Results}

4.1 Survey results

To explore students' perceptions of the summer English program, means and standard deviations of PSEPQ items in both weeks were computed, the results of which are presented in Table 1.

4.1.1 Attitudes towards the courses

As shown in Table 1, the respondents scored 3.40 (item 1) to 3.84 (item 4) on items 1-4 in week 1 and 3.47 (item 1) to 3.79 (item 4) on items 1-4 in week 2, well above the item midpoint 3, meaning that most students liked each of the four courses: Public Speaking, English Debate, Classic Reading and Film dubbing in both weeks. Nevertheless, they scored 2.70 in week 1 and 2.80 in week 2 on the MOOC course, indicating that they generally did not like the course in both weeks. Meanwhile, the participants scored 2.41 to 3.26 in week 1 and 2.38 to 3.41 in week 2 on items 6-8, suggesting that more than half participants believed that the courses were interesting and liked them in both weeks.

4.1.2 Roles of the program

As seen from Table 1, the participants scored 3.13 (item 12) to 3.63 (item 10) in week 1 and 3.39 (item 12) to 3.80 (item 10) in week 2 on items 9-12, all exceeding the item midpoint 3 . This means that, in both weeks, to more than half participants, the program increased their practice of English listening, speaking, reading and writing, with the practice of speaking being the most improved while that of writing being the least improved. Similarly, the participants scored 3.19 (item 16) to 3.61 (item 13) in week 1 and 3.36 (item 16) to 3.70 (item 14) in week 2 on items 13 to 17 , well above the item midpoint 3 . This means that the respondents in both weeks generally endorsed that the program improved their English listening, speaking, reading and writing abilities as well as overall English proficiency, with listening ability being the most enhanced while writing ability being the least enhanced.

In addition, Table 1 shows that the students scored 3.41 (item 20) to 3.55 (item 18) in week 1 and 3.51 (item 21 ) to 3.62 (item 19) on items 18 to 22 , well above the item midpoint 3. This signifies that the program improved the students' interpersonal communication ability, confidence in using English, knowledge of the culture of English-speaking countries, interest in and motivation to learn English in both weeks.

4.1.3 Overall comments on the program

As seen from Table 1, the respondents scored 2.52 (item 25) to 3.58 (item 23) in week 1 and 2.46 (item 25 ) to 3.62 (item 23) in week 2 on items 22 to 26 . This means that the students generally considered the program to be interesting and useful and enjoyed the program in both weeks. 
Table 1. Statistical Analyses of PSEPQ items in Weeks $1 \& 2$

\begin{tabular}{|c|c|c|c|c|c|c|c|}
\hline & \multicolumn{2}{|c|}{ Week 1} & \multicolumn{2}{|c|}{ Week 2} & \multicolumn{3}{|c|}{ Paired-samples t-test results } \\
\hline & M & SD & $\mathrm{M}$ & SD & $\mathrm{t}$ & $\mathrm{p}$ & Cohen's d \\
\hline 1. I like the course Public Speaking. & 3.40 & 1.00 & 3.47 & .96 & -1.81 & .06 & / \\
\hline 2. I like the course English Debate. & 3.49 & 1.06 & 3.66 & .94 & -2.06 & .041 & 0.17 \\
\hline 3. I like the course Classic Reading. & 3.02 & .99 & 3.04 & .90 & -.233 & .816 & l \\
\hline 4. I like the course English Film Dubbing. & 3.84 & 1.09 & 3.79 & .95 & .506 & .613 & / \\
\hline 5. I like the MOOC. & 2.70 & 1.43 & 2.80 & 1.10 & -1.30 & .751 & / \\
\hline 6. I like all the courses. & 3.22 & .107 & 3.41 & 1.00 & -2.17 & .031 & 0.18 \\
\hline 7. All the courses are dull. & 2.41 & 1.09 & 2.38 & 1.09 & .357 & .722 & / \\
\hline 8. All the courses are interesting. & 3.26 & 1.08 & 3.36 & .99 & -1.26 & .209 & / \\
\hline $\begin{array}{l}\text { 9. The program increases my practice of English } \\
\text { listening. }\end{array}$ & 3.59 & 1.01 & 3.67 & .92 & -1.09 & .278 & 1 \\
\hline $\begin{array}{l}\text { 10. The program increases my practice of English } \\
\text { speaking. }\end{array}$ & 3.63 & 1.01 & 3.80 & .84 & -2.28 & .024 & 0.18 \\
\hline $\begin{array}{l}11 . \text { The program increases my practice of English } \\
\text { reading. }\end{array}$ & 3.32 & 1.01 & 3.51 & 1.02 & -2.29 & .023 & 0.19 \\
\hline $\begin{array}{l}\text { 12. The program increases my practice of English } \\
\text { writing. }\end{array}$ & 3.13 & 1.12 & 3.39 & 1.05 & -3.32 & .001 & 0.24 \\
\hline $\begin{array}{l}\text { 13. The program improves my listening English } \\
\text { ability. }\end{array}$ & 3.61 & 1.04 & 3.65 & .95 & -.414 & .679 & 1 \\
\hline $\begin{array}{l}\text { 14. The program improves my spoken English } \\
\text { ability. }\end{array}$ & 3.57 & 1.01 & 3.70 & .87 & -1.51 & .133 & I \\
\hline $\begin{array}{l}\text { 15. The program improves my reading English } \\
\text { ability. }\end{array}$ & 3.30 & 1.08 & 3.45 & .97 & -1.95 & .052 & I \\
\hline $\begin{array}{l}\text { 16. The program improves my writing English } \\
\text { ability. }\end{array}$ & 3.19 & 1.11 & 3.36 & 1.03 & -2.04 & .043 & 0.16 \\
\hline $\begin{array}{l}\text { 17. The program improves my overall English } \\
\text { proficiency. }\end{array}$ & 3.44 & .96 & 3.59 & .91 & -2.02 & .044 & 0.16 \\
\hline $\begin{array}{l}\text { 18. The program improves my interpersonal } \\
\text { communication ability. }\end{array}$ & 3.55 & .97 & 3.63 & .92 & -1.20 & .230 & I \\
\hline $\begin{array}{l}\text { 19. The program improves my confidence of } \\
\text { using English. }\end{array}$ & 3.52 & 1.04 & 3.62 & .95 & -1.23 & .221 & 1 \\
\hline $\begin{array}{l}\text { 20. The program improves my knowledge of the } \\
\text { culture of English-speaking countries. }\end{array}$ & 3.43 & .90 & 3.58 & 1.03 & -1.99 & .048 & 0.16 \\
\hline 21. The program increases my interest in English. & 3.50 & 1.03 & 3.51 & 1.05 & -.175 & .861 & / \\
\hline $\begin{array}{l}\text { 22. The program increases my motivation to learn } \\
\text { English. }\end{array}$ & 3.50 & 1.01 & 3.55 & 1.00 & -.595 & .553 & / \\
\hline 23. The program is interesting. & 3.57 & .93 & 3.62 & .94 & -.647 & .518 & / \\
\hline 24. The program is useful. & 3.50 & 1.02 & 3.58 & 1.02 & -1.09 & .276 & l \\
\hline 25. I don't like the program. & 2.52 & 1.16 & 2.46 & 1.10 & .714 & .476 & I \\
\hline 26. I enjoy the program. & 3.42 & .99 & 3.52 & 1.01 & -1.22 & .223 & I \\
\hline
\end{tabular}

4.1.4 Differences in students' perceptions between weeks 1 and 2

As seen from Table 1, the participants scored higher on all items in week 2 except on items 4, 7, and 25. A lower score on item 7 "All the courses are dull" and item 25 "I don't like the camp" actually means stronger disagreement with the items, indicating that the participants tended more to consider the courses to be interesting and like the program. Statistically significant differences were observed in items $2(\mathrm{t}=-2.06), 6(\mathrm{t}=-2.17), 10(\mathrm{t}=-2.28), 11(\mathrm{t}=-2.29), 12(\mathrm{t}$ $=-3.32), 16(\mathrm{t}=-2.04), 17(\mathrm{t}=-2.02)$, and $20(\mathrm{t}=-1.99)$, though with a small effect size, as evidenced by paired samples t-test results reported in Table1. This means that toward the end of the program (week 2), the participants thought significantly more highly of the course English Debate and other courses in general, believed significantly more 
that the program increased their practice of English speaking, reading and writing and improved their English writing ability and overall English proficiency as well their knowledge of the culture of English-speaking countries.

4.1.5 Responses to the open-ended question

Of 175 survey respondents who responded to the open-ended question in week 1, $127(72.6 \%)$ reported liking the program while $48(27.4 \%)$ expressed dislike for the program. Of 150 survey respondents who responded to the openended question in week 2, $2(1.3 \%)$ neither liked nor disliked the program, $117(78 \%)$ reported liking the program and $31(20.7 \%)$ disliked the program. The results are summarized in Table 2.

Table 2. Self-reported Reasons for Liking/Disliking the Program

\begin{tabular}{|c|c|c|}
\hline \multirow[t]{2}{*}{ Week 1} & Reasons for Liking the program $(\mathrm{N}=127)$ & Reasons for Liking the program $(\mathrm{N}=48)$ \\
\hline & $\begin{array}{l}\text { a) It's (very) interesting }(55 / 43.3 \%) \text {, } \\
\text { b) Learn a lot from it }(30 / 23.6 \%) \text {, } \\
\text { c)The program improves overall English proficiency/English } \\
\text { ability (esp. listening and speaking abilities) }(24 / 18.9 \%) \text {, } \\
\text { d) It offers many opportunities to practice English (esp. } \\
\text { spoken English) }(15 / 11.8 \%) \text {, } \\
\text { e) Learn English in a relaxing circumstance }(13 / 10.2 \%) \text {, } \\
\text { f) It is easy to learn }(8 / 6.3 \%) \text {, } \\
\text { g) It enables me to make/meet a lot of new friends }(6 / 4.7 \%) \text {, } \\
\text { h) It increases my interest in English }(6 / 4.7 \%) \text {, } \\
\text { i) Teachers and classmates are (very) friendly }(5 / 3.9 \%) \text {, } \\
\text { j) It creates an English-learning environment }(4 / 3.1 \%) \text {, } \\
\text { k) It improves my confidence in English }(2 / 1.6 \%) \text {, } \\
\text { 1) The courses are of various types }(2 / 1.6 \%) \text {, } \\
\text { m) It allows me to cooperate with others }(1 / 0.8 \%) \text {, } \\
\text { n) It increases my motivation to learn English }(1 / 0.8 \%) \text {, } \\
\text { o) It reminds me to study English }(1 / 0.8 \%) \text {, } \\
\text { p) Teachers are all responsible ( } 1 / 0.8 \%) \text {, and } \\
\text { q) It's free ( } 1 / 0.8 \%) \text {. }\end{array}$ & $\begin{array}{l}\text { a) Not useful to improve English }(15 / 31.3 \%) \text {, } \\
\text { b) Courses are too easy/a waste of time }(14 / 29.2 \%) \text {, } \\
\text { c) Not interesting/boring }(13 / 27.1 \%) \text {, } \\
\text { d) There are so much homework/so many tasks } \\
\text { ( } 12 / 25 \%) \text {, } \\
\text { e) The time is not used efficiently }(11 / 22.9 \%) \text {, } \\
\text { f) It ruins my after-class time }(3 / 6.3 \%) \text {, } \\
\text { g) Tasks are too difficult }(2 / 4.2 \%) \text {, } \\
\text { h) The time is not used efficiently }(2 / 4.2 \%) \text {, } \\
\text { i) It's tiring to study English with those who are } \\
\text { much better in English }(2.1 \%) \text {, and } \\
\text { j) It takes too long }(2.1 \%) \text {. }\end{array}$ \\
\hline \multirow[t]{2}{*}{ Week 2} & Reasons for Liking the program $(\mathrm{N}=117)$ & Reasons for Liking the program $(\mathrm{N}=31)$ \\
\hline & $\begin{array}{l}\text { a) It's interesting }(64 / 54.7 \%) \text {, } \\
\text { b) It's useful }(34 / 29.1 \%) \text {, } \\
\text { c) I learn a lot from it }(16 / 13.7 \%) \text {, } \\
\text { d) It improves my overall English }(13 / 11.1 \%) \text {, } \\
\text { e) It offers me a chance to use/practice a lot of English } \\
\text { (9/7.7\%), } \\
\text { f) I meet/make a lot of friends }(7 / 6 \%) \text {, } \\
\text { g) It's relaxing ( } 6 / 5.1 \%) \text {, } \\
\text { h) It's easy }(5 / 4.3 \%) \text {, } \\
\text { i) It's good/terrific }(3 / 2.6 \%) \text {, } \\
\text { j) It improves my speaking English }(3 / 2.6 \%) \text {, } \\
\text { k) It increases my interest in English }(2 / 1.7 \%) \text {, } \\
\text { 1) It helps me with my English learning }(2 / 1.7 \%) \text {, } \\
\text { m) It's Inspiring }(2 / 1.7 \%) \text {, } \\
\text { n) It improves my confidence in using English }(1 / 0.9 \%) \text {, } \\
\text { o) It provides a wider perspective of English for me } \\
\text { (1/0.9\%), } \\
\text { p) It improves my fluency in English }(1 / 0.9 \%) \text {, } \\
\text { q) It improves my listening and speaking abilities }(1 / 0.9 \%) \text {, } \\
\text { r) It increases teamwork spirits ( } 1 / 0.9 \%) \text {, } \\
\text { s) I like English }(1 / 0.9 \%) \text {, and } \\
\text { t) I love study ( } 1 / 0.9 \%) \text {. }\end{array}$ & $\begin{array}{l}\text { a) It's boring/not interesting }(10 / 32.3 \%) \text {, } \\
\text { b) It doesn't improve my English } \\
\text { ( } 8 / 25.8 \%) \text {, } \\
\text { c) It's useless }(7 / 22.6 \%) \text {, } \\
\text { d) There are too many tasks }(2 / 6.5 \%) \text {, } \\
\text { e) It's too easy }(2 / 6.5 \%) \text {, } \\
\text { f) It ruins my vacation }(2 / 6.5 \%) \text {, } \\
\text { g) The teaching time is too short }(1 / 3.2 \%) \text {, } \\
\text { h) The MOOC doesn't make sense } \\
\text { (1/3.2\%), } \\
\text { i) The class efficiency is low }(1 / 3.2 \%) \text {, } \\
\text { j) It's not really necessary }(1 / 3.2 \%) \text {, } \\
\text { k) I have to stand my classmates' awful } \\
\text { English ( } 1 / 3.2 \%) \text {, } \\
\text { 1) I can't learn a lot from the program } \\
\text { (1/3.2\%), and } \\
\text { m) We have no right to choose the courses } \\
\text { (1/3.2\%). }\end{array}$ \\
\hline
\end{tabular}

As shown in Table 2, the respondents reported liking the program for such reasons as being interesting (43.3\%), having learnt a lot from it (23.6\%), improving English (18.9\%), having chances to practice English (11.8\%), learning English in a relaxing environment $(10.2 \%)$, being easy to learn $(6.3 \%)$, meeting and/or making friends $(4.7 \%)$, and so on in week 1. $30(23.6 \%)$ students reported having learned a lot from the program such as knowledge of English and strategies to learn the language. For example, as the students confided, “... There are lots of different things to learn" (No. 25, male, week 1), “... It [The program] introduced to me some methods to improve listening and learn English" (No. 72, male, week 1), "I'm exposed to different forms of English and know different ways of practicing English." 
(No.61, male, week 1), “... It provides a perspective of English" (No. 55, female, week 1), “... It gives me some useful advice" (No. 100, male, week 1), "I gained some knowledge on English and its culture" (No. 112, female, week 1), and “... The camp improves my knowledge of the culture of English-speaking countries" (No. 12, male, week 1). 13 $(10.2 \%)$ students commented that the program offered them a relaxing environment to learn English. For example, “... All of the courses are attractive and relaxing, and the schedule of studying is arranged properly and it allows us to have enough time to access more English material (movies and novels)" (No. 44, male, week 1).

Table 2 shows that the students did not like the program due to such reasons as the program failing to improve their English (31.3\%), courses being too easy (29.2\%), homework being too much (25\%), and time being used inefficiently $(22.9 \%)$, in week 1 . The following excerpts were typical responses to the open-ended question. "Some of the courses are too easy and the MOOC is very boring. I think this course is aimed for junior high school students rather than college students" (No. 26, female, week 1). 15 students asserted that the program was not useful to improve their English because it was too short to learn English deeply to have "sufficient opportunities to practice English" (No. 30, male, week 1). A few students commented that the program ruined their after-class time, which made them unable to "enjoy the European Cup these days" (No. 48, male, week 1) or "it's tiring to get up early" (No. 86, male, week 1).

As seen from Table 2, toward the end of the program (week 2), the participants reported liking the program thanks to such reasons as the program being interesting (54.7\%) and useful $(29.1 \%)$, having learned a lot from it (13.7\%), the program improving their English (11.1\%), meeting and/or making friends (6\%), and so on. For example, 16 (13.7\%) participants reported having learned a lot from the program, in that "I learn English in many different ways" (No. 31, male, week 2), "I learn some useful tips" (No. 55, male, week 2), “... It gives me much knowledge about English and western culture. It is very useful" (No. 77, male, week 2), and "I have learned many other things like cultures, music...besides English" (No. 92, male, week 2). 9 (7.7\%) respondents commented that the program provided them with many opportunities to use/practice a lot of English, as it "offers a great English environment for us, for which we can immerse in English and improve our overall skills of English" (No. 105, male, week 2).

Table 2 shows that in week 2, the participants did not like the program for such reasons as the program being boring $(32.3 \%)$ and useless $(22.6 \%)$ and failing to improve their English $(25.8 \%)$, tasks being too many $(6.5 \%)$, the teaching time being too short $(3.2 \%)$, and so on. 8 students confided that the program failed to improve their English, as “... It seems we can gain some knowledge from the program, but I really feel it's just not the best way to learn English. I mean it's just too much there for the little progress" (No. 67, male, week 2), “... It's too easy and therefore useless for those with an advanced English ability" (No. 98, male, week 2).

4.2 Result of the interview data

4.2.1 Self-reported like/dislike for the courses

Table 3. Self-reported Like/Dislike for the Courses $(\mathrm{N}=19)$

\begin{tabular}{|c|c|c|c|c|c|c|c|c|c|}
\hline \multirow{3}{*}{$\begin{array}{l}\text { Week } \\
1\end{array}$} & \multirow{3}{*}{ Course } & \multicolumn{4}{|c|}{ Most liked courses } & \multicolumn{4}{|c|}{ Least liked courses } \\
\hline & & Film dubbing & Debate & Classic & Speech & Classic & Film & MOOC & Speech \\
\hline & & $5(26.3 \%)$ & $5(26.3 \%)$ & $\begin{array}{l}\text { reading } \\
4(21.1 \%)\end{array}$ & $3(15.8 \%)$ & $\begin{array}{l}\text { reading } \\
4(21.1 \%)\end{array}$ & $\begin{array}{l}\text { Dubbing } \\
3(15.8 \%)\end{array}$ & $2(10.5 \%)$ & $1(5.3 \%)$ \\
\hline & Reasons & Interesting, & Interesting & Learn & Interesting & Dull & Not useful & Too easy & Not \\
\hline & & & Much & English & & & & & demanding \\
\hline & & $\begin{array}{l}\text { Much } \\
\text { participation }\end{array}$ & participation & & & & & & \\
\hline \multirow{8}{*}{$\begin{array}{l}\text { Week } \\
2\end{array}$} & Course & Debate & Film dubbing & Speech & Classic & Classic & Film & Debate & \\
\hline & & $8(42.1 \%)$ & $6(31.6 \%)$ & $2(10.5 \%)$ & reading & reading & dubbing & $1(5.3 \%)$ & \\
\hline & & & & & $1(5.3 \%)$ & $11(57.9 \%)$ & $2(10.5 \%)$ & & \\
\hline & Reasons & Learn a lot & Improve & Lots of & Know more & Dull, little & Not much & Poor oral & \\
\hline & & & pronunciation & participation, & about a writer & participation & useful & English & \\
\hline & & & and intonation & & & & & & \\
\hline & & & & critical & & & & & \\
\hline & & & & thinking & & & & & \\
\hline
\end{tabular}

As reported in Table 3, in week 1, 5(26.3\%), 5(26.3\%), 4(21.1\%) and 3(15.8\%) interviewees reported liking Debate, Film Dubbing, Classic Reading and Speech the most respectively, largely because the courses were interesting and required much participation. As they reported, "I like Debate more, because it involves more students and requires much student participation. It also improves my thinking ability during the process as well as my listening and speaking. Besides, when preparing for the debate, we can learn English and know more about the current affairs" (Sun, male, week 1), "I like English Debate the most, because it is very interesting, offers me much space to plan and develop my ideas. And I have an opponent, so it is quite exciting as well” (Li, male, week 1), “... I like English Speech the most. The teacher teaches in an interesting way and creates a very good classroom atmosphere. Everything is in English 
and formal, and we have to participate and be attentive" (Huang, male, week 1), and "Film dubbing is fairly interesting and entertaining" (Xu, male, week 1).

Largely for similar reasons, in week 2, 8(42.1\%) interviewees reported liking English Debate, 6(31.6\%) Film Dubbing, and $2(10.5 \%)$ English Speech the most respectively. As reported by the interviewees, "the classroom atmosphere is really good in Debate, everyone is free to speak. It is really interesting” (Xu, male, week 2), “... I am the most devoted to Speech. I think it is good to me to correct pronunciation and intonation, and imitate others" (Sun, male, week 2).

In both weeks, the interviewees did not like a course largely because it was boring and required little participation or not useful. For example, "I don't like Classic Reading at all, because it is so dull. The teacher talks, talks and talks, we just listen, listen and listen. We have little participation" (Sun, male, week 1), and “... It [Classic Reading] is too boring. We just listen in class. Actually we forget soon what we hear. It is meaningless" (Yang, male, week 2).

4.2.2 Self-reported practice of and progress in English speaking, listening, reading and writing

Table 4. Self-reported practice of English speaking, listening, reading and writing

\begin{tabular}{llllll}
\hline \multirow{2}{*}{ Week 1 } & Increased & $19(100 \%)$ & $18(94.7 \%)$ & $6(31.6 \%)$ (not much) & 0 \\
\cline { 2 - 6 } & (almost) No & 0 & 1 & $13(68.4 \%)$ & $19(100 \%)$ \\
\hline Week 2 & Increased & $18(94.7 \%)$ & $18(94.7 \%)$ & $6(31.6 \%)($ not much) & 0 \\
\cline { 2 - 6 } & (almost) No & $1(5.3 \%)$ & $1(5.3 \%)$ & $13(68.4 \%)$ & $19(100 \%)$ \\
\hline
\end{tabular}

As shown in Table 4, in week 1, all the interviewees reported that the program increased their practice of English speaking. For example, “... It of course increases the opportunity to speak English, for example we have to speak in courses like Speech, Debate, Film Dubbing, and practice a lot when working on the tasks for the courses" (Sun, male, week 1), "We often have the chance to speak English once a week during the semester, but we have to speak English every day during the program" (Xu, male, week 1$)$. Similarly, they all except 1 claimed that the program increased their practice of English listening, because "most courses are conducted in English, and we have to finish the tasks in English. This is really good. I have never been in such an environment except in the English Club" (Yu, male, week 1), “... The teachers speak English, and I have to understand them to be sure what I'm required to do" (Xu, male, week 1).

Although there was one reading course "Classic Reading", it did not require students to work on any specific task, the interviewees generally commented that they did not practice reading much. Nevertheless, because they had to read to prepare for courses like Film Dubbing, Speech and Debate, they increased their English reading practice more or less. Because no writing course or task was required, the interviewees generally did not endorse that the program increased their practice of English writing.

It was almost the same in week 2: 18 students reported having had more practice of English speaking and listening, while 13 and 19 reported having no or little practice of English reading and writing, respectively, for similar reasons. For example, "I have little practice during the semester. But in the program, I have more opportunities to practice English. For example, my classmates and I often spend a couple of hours practicing dubbing in the afternoon or evening" (Sun, male, week 2).

Table 5. Self-reported Progress in English speaking, listening, reading and writing Abilities (N=19)

\begin{tabular}{|c|c|c|c|c|c|c|}
\hline & & $\begin{array}{l}\text { English } \\
\text { speaking }\end{array}$ & $\begin{array}{l}\text { English } \\
\text { listening }\end{array}$ & $\begin{array}{l}\text { English } \\
\text { reading }\end{array}$ & $\begin{array}{l}\text { English } \\
\text { writing }\end{array}$ & $\begin{array}{l}\text { Overall English } \\
\text { proficiency }\end{array}$ \\
\hline \multirow[t]{3}{*}{ Week 1} & Improved & $17(89.5 \%)$ & $16(84.2 \%)$ & $\begin{array}{l}11(57.9 \%) \\
\text { (not much) }\end{array}$ & 0 & $16(84.2 \%)$ \\
\hline & Not sure & $2(10.5 \%)$ & $2(10.5 \%)$ & $2(10.5 \%)$ & $5(26.3 \%)$ & $1(5.3 \%)$ \\
\hline & No & 0 & $1(5.3 \%)$ & $6(31.6 \%)$ & $14(73.7 \%)$ & $2(10.5 \%)$ \\
\hline \multirow[t]{4}{*}{ Week 2} & Improved & $15(78.9 \%)$ & $15(78.9 \%)$ & $\begin{array}{l}6(31.6 \%) \quad(a \\
\text { little })\end{array}$ & 0 & $14(73.7 \%)$ \\
\hline & $\begin{array}{l}\text { Maintained the } \\
\text { sense of language }\end{array}$ & $1(5.3 \%)$ & $1(5.3 \%)$ & 0 & 0 & 0 \\
\hline & No & $2(10.5 \%)$ & $2(10.5 \%)$ & $6(31.6 \%)$ & 19 & $4(21.1 \%)$ \\
\hline & Not sure & 0 & 0 & 0 & 0 & $1(5.3 \%)$ \\
\hline
\end{tabular}

Table 5 summarizes the interviewees' reported progress in English abilities. As seen from Table 5, in week 1, mainly thanks to the increased practice in English listening and speaking, 17(89.5\%) and 16(84.2\%) interviewees respectively reported that their speaking and listening English was improved during the program. As Xia (male, week 1) reflected, 
"because we used it much, naturally our listening and speaking English abilities were improved". Two interviewees confessed that because the program was too short, there would not be obvious progress in their English listening and speaking abilities. Because "the program predominantly focuses on speaking and listening" (Sun, male, week 1), $11(57.9 \%)$ students believed that they had some progress in English reading during the program, while 6(31.6\%) reported having no progress at all. In terms of overall English proficiency, $16(84.2 \%)$ interviewees believed their overall English proficiency was improved during the program, in that "I have so much exposure and access to English in different courses. I use it every day, and so naturally my overall English gets better" (Sun, male, week 1).

Their opinions did not change much in week 2, as shown in Table 5: 15(78.9\%) interviewees reported having improved their speaking and listening English respectively, 6(31.6\%) believed that the program improved their English reading ability in that "there are some strange words in the essays, and I have to understand long sentences" (He, male, week 2). In terms of overall English proficiency, 14(73.7\%) interviewees claimed that the program temporarily improved their ability to comprehend and speak English because they had to use it every day but 1(5.3\%) was not sure "whether it could improve my overall English proficiency in the long run" (Huang, male, week 2). Moreover, 2(10.5\%) interviewees in week 1 and 6(31.6\%) in week 2 reflected that the program increased their knowledge of the English culture.

\subsubsection{Self-reported effects of the program on other aspects of English learning}

In addition to the effects on the practice of and progress in English listening, speaking, reading and writing abilities, the interviewees claimed that the program positively affected their learning of English in other aspects in week 1 . These aspects include: a) increased interpersonal communication ability $(6 / 31.6 \%)$, b) increased knowledge of the English culture $(6 / 31.6 \%)$, c) more strategies to learn English $(5 / 26.3 \%)$, d) increased confidence in English $(3 / 15.8 \%)$, e) increased interest in English (2/10.5\%), and f) increased knowledge of the English language (2/10.5\%). As commented by the interviewees, "... My confidence in English increased the most. The everyday access to English unconsciously increases my confidence and my knowledge of British and American cultures, (Yu, male, week 1), “... I am exposed to different kinds of English courses and activities, which are so different from the formal classroom learning. This increases my interest in English" (Long, male, week 1), “... I learnt different methods from different teachers. This improves the effectiveness of my English learning” (Long, male, week 1), “... I know more about the English culture and its way of thinking. English Debate trains our thinking ability in English. I also learn more about spoken English in the Film Dubbing course, which enables me to be braver to speak English. In addition, the teachers and their assistants introduced some strategies to learn English, which should be helpful in the future" (Li, male, week 1).

In week 2, the interviewees commented that the program helped a) increase thier confidence in English (7/36.8\%), b) increase thier interest in English $(6 / 31.6 \%), c)$ them make more friends $(5 / 26.3 \%), d)$ them learn more English learning strategies $(3 / 15.8 \%)$, e) them have a deeper understanding of the English culture $(2 / 10.5 \%)$, f) increase their interest in communicating with others in English $(2 / 10.5 \%)$, g) them accumulate vocabulary $(1 / 5.3 \%)$, and $h)$ them have a deeper understanding of the tasks (1/5.3\%). For example, “... I think I have learned English-learning strategies and increased my interest in English. For example, in the class, the teachers often talk about different kinds of knowledge, such as differences in pronunciation, ways to debate, ways to organize speech, and so on” (Li, male, week 2), “... I won't fear talking to foreigners anymore. Even if I can't understand, I dare to talk to them now" (Luo, male, week 2).

\subsubsection{General comments on and suggestions for the program}

When asked to comment on the summer English program, the interviewees listed the following features of the program in week 1: a) interesting $(17 / 73.7 \%)$, b) useful $(9 / 47.4 \%)$ and c) heavily loaded (3/15.8\%). As confided by the interviewees, "The camp is generally very interesting. English Speech, Debate andFilm Dubbing are all interesting. The teacher of the Classic Reading course moves quite fast, and helps me with difficulties in terms of grammar and cultural differences" (Xu, male, week 1). "The camp is useful", because I "get to know many teachers and assistants" (Yu, male, week 1), "increase my confidence in English (Yu, male, week 1), and "have the chance to access English" (He, male, week 1). "The camp has too many tasks" (Yang, male, week 1).

Based on their own experiences with the program, they voiced the following suggestions to make the program better in the future in week 1 .

Table 6. Suggestions for the Program $(\mathrm{N}=19)$

Week 1
$\begin{array}{ll}\text { a) MOOC should be excluded from the program } & \text { a) Have more communication with teachers and peer } \\ \text { students }(6 / 31.6 \%),\end{array}$
$\begin{array}{ll}(8 / 42.1 \%), \\ \text { b) Offer more advice and guidance on English learning } & \text { b) Allow students to choose courses freely }(5 / 26.3 \%), \\ (7 / 36.8 \%), & \text { c) Have more class hours }(3 / 15.8 \%), \\ \text { c) Offer more courses for students to choose }(5 / 26.3 \%), & \text { d) Have more practice }(3 / 15.8 \%), \\ \text { d) Assign more tasks }(3 / 15.8 \%), & \text { e) Increase the difficulty of the tasks }(2 / 10.5 \%), \\ \text { e) Assign tasks more properly }(2 / 10.5 \% /), & \text { f) Be longer }(2 / 10.5 \%), \\ \text { f) Have writing practice }(2 / 10.5 \%), & \text { g) Have more activities }(2 / 10.5 \%),\end{array}$


g) Mix students of different disciplines in the same class $(1 / 5.3 \%)$,

h) Average the number of students for each class $(1 / 5.3 \%)$,

i) Offer courses in the afternoon as well $(1 / 5.3 \%)$

J) Include international students (1/5.3\%),

k) Have the same course consecutively $(1 / 5.3 \%)$. h) Be more focused $(2 / 10.5 \%)$

i) Have more focused intensive training $(1 / 5.3 \%)$,

j) Start later $(1 / 5.3 \%)$,

k) Average the number of students for each class (1/5.3\%),

1) Assign some big projects (1/5.3\%).

m) Have writing tasks $(1 / 5.3 \%)$,

n) Cancel MOOC (1/5.3\%),

As shown in Table 6, the students voiced a number of suggestions in week 1 to make the program better, such as offering more courses, more advice and guidance on how to learn English, mixing students from diverse disciplines in the same class and including international students to make the class more interesting. Because "MOOC is too easy", $8(42.1 \%)$ interviewees suggested excluding it from the program and having other courses more appropriate to their English proficiency level and personal needs. Since almost every course had tasks, the interviewees considered it better to take into account students' time, and personal preferences when scaffolding the tasks. Also, it might cater more to the students if more courses such as TOEFL, GRE, College English Test bands 4 or 6, and English writing could be offered.

As the program progressed to the second week, the interviewees had the following comments on the program: a) it was (very) interesting $(6 / 31.6 \%)$, b) it enabled us to access more different things such as dubbing strategies and accents $(5 / 26.3 \%), c)$ it enabled us to have more communication with teachers and students $(4 / 21.1 \%)$, d) it was meaningful $(2 / 10.5 \%)$, and e) it was different from routine formal classroom teaching and learning $(1 / 5.3 \%)$. The suggestions were similar to those in week 1 as well. One difference was that some interviewees suggested having more focused intensive training in that "they can do general training themselves" (Long, male, week 2) and assigning some big projects "which required longer time and more efforts and participation" (He, male, week 2). Thus, they could learn something in the real sense.

\section{Discussion}

\subsection{Perceptions of the summer English program}

Analyses of the data showed that in both weeks, most students considered the courses interesting and liked most of the courses except MOOC for similar reasons such as being interesting and having much participation. This was largely because, as the students commented themselves, "Film Dubbing, English Debate and Speech are so interesting and new to us. We have seldom accessed either of the courses in routine classroom teaching and learning" (Sun, male, week 1) and the courses required much participation, cooperation, independent thinking and practice/use of English. On the contrary, MOOC, originally designed for English teachers of primary and middle schools in the underdeveloped areas of China, apparently was too easy to the students of the university, most of whom were at a relatively high English proficiency level. Because almost each course was (quite) demanding, requiring students to complete a series of tasks individually or collaboratively in English, the program offered opportunities much more than usual to them to practice and use English, especially English speaking and listening in both weeks. This naturally led to progress in their English abilities in four different aspects (i.e., listening, speaking, reading and writing) as well as overall English proficiency in both weeks. English writing was the least practiced and the least improved probably due to the fact that the program predominantly focused on listening and speaking. Though the teachers did not lecture much in class, they discussed and/or shared such things with students such as task-specific strategies and the English culture. Therefore, in both weeks, more than half participants reported that the program improved their interpersonal communication ability, confidence in using English, knowledge of the culture of English-speaking countries, interest in and motivation to learn English. As they remarked, "I have learnt a lot from the camp" (No. 33, male, week 2) and "come to know more about the American culture" (No. 51, female, week 2) and "the camp provides me with a wider perspective" (No. 89, male, week 2). Consequently, in both weeks, the students generally considered the program to be interesting and useful and enjoyed the program largely for similar reasons in both weeks. All these findings are mainly owing to the fact that the program provided the students with enormous access to the TL, as evidenced in current studies (Alcòn-Soler, 2015; DeKeyser, 2007; Liskin-Gasparro, 1998; Pang \& Liu, 2005; Rugasken \& Harris, 2006; Savage \& Hughes, 2014).

\subsection{Changes in the perceptions of the summer English program}

Statistical analyses (see Table 1) showed that the participants tended to become more positive about the program in week 2. In particular, they thought significantly more highly of the course English Debate and other courses in general, believed significantly more that the program increased their practice of English speaking, reading and writing and improved their English writing ability and overall English proficiency as well as their knowledge of the culture of English-speaking countries in week 2. Analyses of the qualitative data also revealed that the participants had a more comprehensive view of the program and tended to assess it more objectively toward the end of the program. This not only reflects that foreign language learning is a process but also shows that the participants were independent, active and reflective learners.

Although the students generally held positive attitudes towards the program, what is worth noting is that they offered a number of suggestions to make it better, such as offering more courses, more advice and guidance on how to learn 
English, mixing students from diverse disciplines in the same class and having more focused intensive training in weeks 1 and 2. This indicates that there is room for the program to become better. To better cater to students' personal needs and interests, it might be helpful to do a needs analysis prior to the program, so that specific courses and tasks can be prepared instead of imposing them on the students, as discussed in Liu and Liu (2008). The program then might be both interesting and helpful. Moreover, as discussed in Swain \& Lapkin (1989, p.150), it is paramount to provide an "integration of content teaching and language teaching", which can allow students to immediately apply the newly acquired knowledge in class to use in their real life. It is thus more useful to design a series of content-based courses conducted in English for the summer English program, so that students can learn "real things" (Yang, male, week 2) while having fun at the same time.

\section{Conclusion}

The present research examined university students' perceptions towards a 2-week summer English immersion program organized and designated by Chinese teachers of English in a highly prestigious university in Beijing and changes in the perceptions during the period. The results showed that most participants were (fairly) positive about the program in both weeks, and that they tended to become more positive about it, have a more comprehensive view of it and assess it more objectively toward the end of the program. These findings mean that the program benefited the students in various aspects. This is fairly inspiring if similar programs are to be established in other similar FL contexts. Nevertheless, to guarantee or enhance the effectiveness of the programs, it is wise to do a needs analysis in advance so that more acceptable courses and activities can be designed.

Acknowledgement: Sincere thanks go to all the participants who made this study and the paper possible.

\section{References}

Alcòn-Soler, E. (2015). Pragmatic learning and study abroad: Effects of instruction and length of stay. System, 48, 6274.

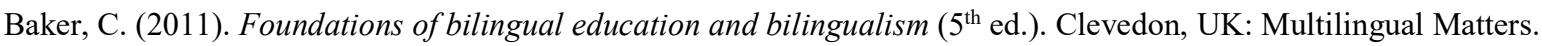

Baker, S. C., and MacIntyre, P. D. (2000). The role of gender and immersion in communication and second language orientations. Language Learning, 50(2), 311-341.

Chlebek, A., and Coltrinari, H. (1977). Summer immersion programs abroad. Canadian Modern Language Review, 33, 348-53.

Cummins, J. (1983). Mother tongue development as educational enrichment: Research finding. In J. Cummins (ed.), Heritage language education: Issues and directions (pp. 40-43). Ottawa: Multiculturalism Canada.

DeKeyser, R. (2007). Study abroad as foreign language practice. In R. DeKeyser (ed.), Practice in a second language: perspectives from applied linguistics and cognitive psychology (pp. 208-226). N.Y: CUP.

Garcia, M., \& Torres-Ayala, V. (1991). Immersion for native speakers-The UCLA-Guadalajara program. Hispania, 74(2), 439-445.

Gardner, R. C. (1985). Social psychology and second language learning: The role of attitudes and motivation. London: Edward Arnold.

Gebauer, S. K., Zaunbauer, A. C., \& Moller, J. (2013). Cross-language transfer in English immersion programs in Germany: Reading comprehension and reading fluency. Contemporary Educational Psychology, 38, 64-74.

Genesee, F. (2004). What do we know about bilingual education for majority-language students? In T. K. Bhatia \& W. C. Ritchie (eds.), The handbook of bilingualism (pp. 547-576). Malden, MA: Blackwell.

Jimenez, A. F. (2003). Linguistic and psychological dimensions of second language attrition during and after a study abroad experience. Unpublished Ph.D dissertation, the Pennsylvania State University.

Kang, S. (2005). Dynamic emergence of situational willingness to communicate in a second language. System, 33, 22792.

Liu, L., \& Liu, M. (2008). Need analysis and its impact on college English teaching. Foreign Language Research (Chinese), 6, 68-73.

Liskin-Gasparro, J. (1998). Linguistic development in an immersion context: How advanced learners of Spanish perceive SLA. The Modern Language Journal, 82(2), 159-175.

MacIntyre, P. D., Clément, R., Dörnyei, Z., \& Noels, K. A. (1998). Conceptualizing willingness to communicate in a L2: a situational model of L2 confidence and affiliation. The Modern Language Journal, 82(4), 545-562.

Martinsen, R. (2011). Predicting changes in cultural sensitivity among students of Spanish during short-term study abroad. Hispania, 94(1), 121-141.

Nunes, J. C., Rosario, P., Vallejo, G., \& Gonzalez-Pienda, J. A. (2013). A longitudinal assessment of the effectiveness of a school-based mentoring program in middle school. Contemporary Educational Psychology, 38, 11-21. 
Pang,S.-M., \& Liu, M. (2006). Chinese students' perspectives on a school-based English program. Indonesian Journal of English Language Teaching, 2(1), 54-71.

Richards, L. (2009). Handling qualitative data. Thousand Oaks, CA: Sage.

Rifkin, B. (2005). A ceiling effect in traditional foreign language instruction: Data from Russian author(s). The Modern Language Journal, 89 (1), 3-18.

Rugasken, K., \& Harris, J. A. (2006). English camp: A language immersion program in Thailand. TLAR, 14(2), 43-51.

Savage, B. L., \& Hughes, H. Z. (2014). How does short-term foreign language immersion stimulate language learning? Frontiers: The Interdisciplinary Journal of Study Abroad, XXIV, 103-120.

Shively, R. L. (2008). Politeness and social interaction in study abroad: Service encounters in L2 Spanish. Unpublished $\mathrm{Ph} . \mathrm{D}$ dissertation, the University of Minnesota.

Swain, M., \& Lapkin, S. (1989). Canadian immersion and adult second language teaching: What's the connection? The Modern Language Journal, 73(2), 150-159.

Walker, C., \& Tedick, D. (2000). The complexity of immersion education: Teachers address the issues. The Modern Language Journal, 84(1), 5-27.

Vygostky, L. S. (1978). Mind in society: The development of higher psychological processes. Cambridge, MA: Harvard University Press. 